\title{
Reimbursement for Supportive Cancer Medications Through Private Insurance in Saskatchewan
}

\author{
Lindy Forte, Colleen Olson, Carolyn Atchison, and Kathy Gesy
}

\begin{abstract}
Background: As demand for cancer treatment grows, and newer, more expensive drugs become available, public payers in Canada are finding it increasingly difficult to fund the full range of available cancer drugs.

Objective: To determine the extent of private drug coverage for supportive cancer treatments in Saskatchewan, preparatory to exploring the potential for cost-sharing.

Methods: Patients who presented for chemotherapy and who provided informed consent for participation were surveyed regarding their access to private insurance. Insurers were contacted to verify patients' level of coverage for supportive cancer medications. Groups with specified types of insurance were compared statistically in terms of age, income bracket, time required to assess insurance status, and amount of deductible. Logistic regression was used to determine the effect of patients' age and income on the probability of having insurance.

Results: Of 169 patients approached to participate, 156 provided consent and completed the survey. Their mean age was 58.5 years. About two-fifths of all patients ( 64 or $41 \%$ ) were in the lowest income bracket (up to $\$ 30000)$. Sixty-three ( $40 \%$ ) of the patients had private insurance for drugs, and $36(57 \%)$ of these plans included reimbursement for supportive cancer medications. A deductible was in effect in 31 (49\%) of the plans, a copayment in $28(44 \%)$, and a maximum payment in $8(13 \%)$. Income over $\$ 50000$ was a significant predictor of access to drug insurance $(p=0.003)$, but age was not significantly related to insurance status.

Conclusions: A substantial proportion of cancer patients in this study had access to private insurance for supportive cancer drugs for which reimbursement is currently provided by the Saskatchewan Cancer Agency. Cost-sharing and optimal utilization of the multipayer environment might offer a greater opportunity for public payers to cover future innovative and supportive therapies for cancer, but further study is required to determine whether a cost-sharing program would be cost-effective and in the best interest of patients.
\end{abstract}

Key words: private payer, reimbursement, Canada, cancer, cost-sharing

Can J Hosp Pharm 2009;62(3):232-237

\section{RÉSUMÉ}

Contexte : Avec la demande croissante pour les traitements anticancéreux, et l'arrivée de nouveaux médicaments plus coûteux, les payeurs publics canadiens ont de plus en plus de difficultés à rembourser toute la gamme de médicaments anticancéreux maintenant offerts.

Objectif : Déterminer dans quelle proportion les médicaments adjuvants des anticancéreux sont remboursés par les régimes privés d'assurance médicaments en Saskatchewan, avant d'évaluer la possibilité du partage des coûts.

Méthodes : Les patients qui se sont présentés à une séance de chimiothérapie et qui ont donné leur consentement éclairé à participer au sondage ont répondu à un questionnaire sur leur couverture d'assurance médicaments privée. Un suivi auprès des assureurs de chaque patient a permis de vérifier la couverture offerte pour les médicaments adjuvants des anticancéreux. Les groupes de patients ayant chacun un type défini d'assurance ont été comparés pour ce qui est des critères suivants : âge, tranche de revenu, délai d'évaluation de la couverture d'assurance et montant de la franchise. Un modèle de régression logistique a servi à déterminer l'effet de l'âge et du revenu des patients sur la probabilité d'avoir une assurance.

Résultats : Des 169 patients sollicités pour participer au sondage, 156 ont donné leur consentement et répondu au sondage. L'âge moyen était de 58,5 ans. Environ deux cinquièmes des patients (64 ou $41 \%)$ se situaient dans la tranche de revenu le plus faible (jusqu'à $30000 \$$ ). Soixante-trois $(40 \%)$ des patients détenaient une assurance médicaments privée, et 36 (57\%) de ces assurances remboursaient les médicaments adjuvants des anticancéreux. Les franchises étaient en vigueur pour 31 (49\%) des assurances, les coassurances pour $28(44 \%)$ et les remboursements maximums pour $8(13 \%)$. Un revenu supérieur à $50000 \$$ était un facteur prédictif significatif d'accès à une assurance médicaments $(p=0,003)$, mais pas l'âge.

Conclusions : Une proportion considérable de patients atteints de cancer dans cette étude avaient accès à un régime privé d'assurance couvrant les médicaments adjuvants des anticancéreux qui étaient actuellement remboursés par la Saskatchewan Cancer Agency. Le partage des coûts et l'utilisation optimale du contexte de payeurs multiples permettraient aux payeurs publics de rembourser de futurs traitements novateurs et adjuvants du cancer, mais d'autres études sont nécessaires pour déterminer si un programme de partage des coûts serait rentable et dans le meilleur intérêt des patients.

Mots clés : payeur privé, remboursement, Canada, cancer, partage des coûts

[Traducti0on par l'éditeur] 


\section{INTRODUCTION}

$\mathrm{T}$ The Canada Health Act is intended to ensure that all residents of Canada have reasonable access to medically necessary services without direct payments. ${ }^{1}$ Based on this principle of universal health care, the provinces and territories of Canada provide medically necessary hospital services, physician services, and surgical and dental services to citizens in each jurisdiction. ${ }^{1}$ In addition to reimbursing health care institutions for inpatient and outpatient medical services and medications that patients require during hospital stays, all provincial ministries of health have drug programs to pay for medications that citizens require on an outpatient basis. Although the structure of these outpatient drug programs varies considerably among provinces, coverage is generally provided for patients over the age of 65 and those who receive social assistance.

Public health care budgets are becoming increasingly strained, in part because of the aging of the population and the rising demand for health care resources. ${ }^{2}$ The provinces and territories differ in terms of their total per capita health expenditures and their expenditures on drugs in particular. ${ }^{2}$ Reimbursement for medications, including reimbursement for cancer drugs, varies across the country ${ }^{3-6}$ because of differences in health policy and the resulting extent of formulary listings. ${ }^{2}$ Now, more than ever, provincial ministries of health have begun to find novel ways to ensure that scarce resources are allocated efficiently to the most patients with the greatest need. Some provinces have aimed to increase efficiency through cost-sharing, whereby patients must pay deductibles or copayments. ${ }^{2}$ Other provinces have instituted reference pricing, whereby lower-cost medications are defined as "reference treatments"; patients and prescribers may opt for higher-cost medications, but if so, the patient must pay the differential out of pocket. $^{2}$

Patient-based cost-sharing and other restrictive reimbursement mechanisms may not be ideal, as they have been associated with negative health outcomes. ${ }^{7.8}$ Other options must therefore be explored. One potential solution may be to share costs with private insurers, whereby public drug plans could restrict their coverage to patients without any private insurance and/or reimburse patients only for drug costs not paid through their private insurance plans. In effect, the public drug plan would become the payer of last resort for all patients.

In Saskatchewan, the Saskatchewan Cancer Agency provides a $100 \%$ benefit for all formulary cancer drugs and some supportive-care drugs specific to cancer patients. These cancer medications and supportive drugs are not listed on the formulary of the provincial drug program (the Saskatchewan Prescription Drug Plan). With the steady rise in the number of new cancer treatments available, ${ }^{6}$ the pressure on the
Saskatchewan Cancer Agency's budget is increasing.' The objective of this project was to determine the extent of private drug coverage among cancer patients in Saskatchewan, preparatory to exploring the potential for sharing the costs of supportive cancer medications with private health care payers.

\section{METHODS}

Three final-year pharmacy students approached patients who presented for chemotherapy at the Saskatoon Cancer Centre between January and April 2006. The students explained the purpose of the study to the patients and asked the patients to provide written consent to participate. Data were obtained only from consenting patients. The pharmacy students used a structured questionnaire to assess patients' private reimbursement for medication therapy. The data gathered included patients' demographic characteristics (age, cancer diagnosis, and family income), information on the availability and extent of private insurance for each patient and/or his or her partner, the name of the patient's insurance company and his or her insurance plan number, and the start and end time for each patient interview. For patients who reported that they had private insurance that included reimbursement for prescription drugs, study personnel followed up with the insurers to determine if supportive medications specific for cancer patients (which are usually provided through the Saskatchewan Cancer Agency and are not listed by the Saskatchewan Prescription Drug Plan) were covered by the patient's private insurance plan. Patient-reported copayments and deductibles were also verified.

Data were analyzed using SPSS statistical software (version 15.0; SPSS Inc, Chicago, Illinois). Patients were considered eligible for inclusion in the analysis if they had consented to participate and had provided sufficient information about their insurance plans for the researchers to verify their eligibility for drug reimbursement. Means were calculated for patient age, the time required to assess insurance status, and deductibles. Analysis of variance (ANOVA) was used to compare means between groups of patients with different types of insurance. $\chi^{2}$ and Fisher's exact tests were used to compare proportions of patients according to cancer type, income bracket, age group (under 65 years of age or 65 years and older), and extent of private insurance coverage (i.e., whether medications were covered and, if so, whether cancer medications were included in the plan). Logistic regression was used to model the effect of patients' age and income on the probability of having private insurance. Logistic regression was used because the outcome variable was binary (yes or no) and one of the predictors was continuous (age). Income was treated as a categorical variable, with 4 levels as defined in Table 1. 


\section{Table 1. Proportion of Patients in Each Income} Category

\begin{tabular}{lcc} 
Income Range (\$) & No. (\%) of Patients \\
\hline$\leq 30000$ & 64 & $(41)$ \\
$>30000$ to 50000 & 40 & $(26)$ \\
$>50000$ to 75000 & 30 & $(19)$ \\
$>75000$ & 22 & $(14)$ \\
\hline
\end{tabular}

\section{RESULTS}

\section{Demographic Characteristics}

In total, 169 consecutive patients were approached, of whom 156 consented and had evaluable data for the analysis. Of the 3 patients who declined to participate, difficulty living with cancer or the side effects of their medications and not wanting to be part of a study were the cited reasons. For 10 other patients, the data were not evaluable because they did not provide follow-up information about their insurance.

The mean age of all patients was 58.5 years $(95 \%$ confidence interval [CI] 56.4-60.6 years), and 55 (35\%) of the patients were 65 years of age or older. The most common cancer site was the breast ( 51 or $33 \%$ of cancers). The frequency of breast cancer was more than twice that of the next most common cancers: colorectal (21 or 13\%), non-small-cell lung cancer (17 or $11 \%)$, and lymphoma (16 or $10 \%$ ) (Figure 1 ).

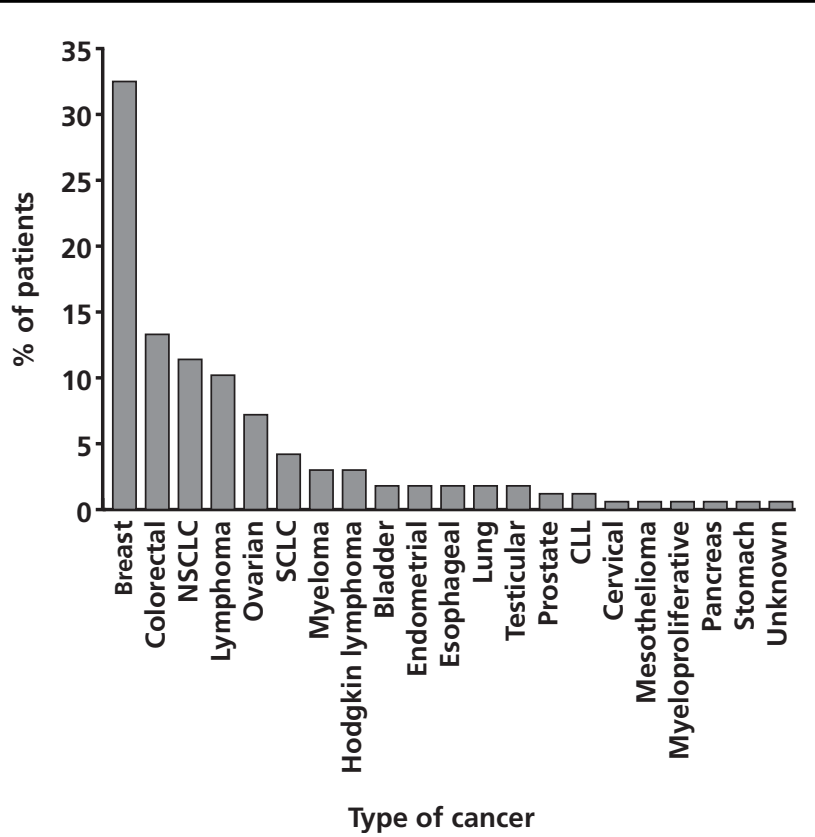

Figure 1. Main diagnosis for study participants $(n=156)$. NSCLC $=$ non-small-cell lung cancer, $\mathrm{SCLC}=$ small-cell lung cancer, $\mathrm{CLL}=$ chronic lymphocytic leukemia.

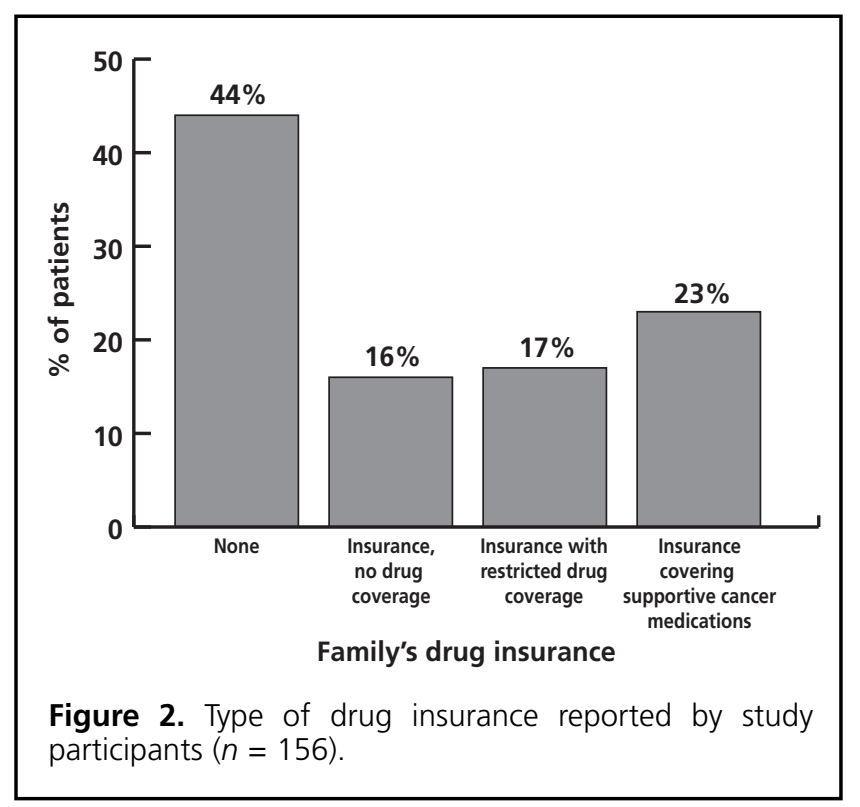

\section{Patient Income}

Two-thirds of the patients (104 or 67\%) earned an annual income of $\$ 50000$ or less (Table 1). Two-fifths of all patients were in the lowest income bracket (up to $\$ 30000$ ).

\section{Private Insurance Coverage}

In total, $87(56 \%)$ of patients had some form of private medical insurance (Figure 2): 67 (43\%) of all patients reported having insurance of their own (95\% CI $35.7 \%$ to $50.1 \%)$, and an additional 20 patients (13\%) had access to their partner's plan $(95 \%$ CI $7.6 \%$ to $18.1 \%)$. Of the medical insurance plans, nearly $72 \%$ (95\% CI $62.0 \%$ to $81.1 \%$ ) included reimbursement for medications. Overall, $63(40 \%)$ of the patients had private insurance coverage for drugs.

Follow-up with drug plan administrators revealed that more than half of the insurance plans that provided reimbursement for drugs (i.e., 36 of the 63 plans) extended coverage to supportive cancer medications administered on an outpatient basis to treat anemia and to prevent febrile neutropenia (Figure 2). The remainder of the drug insurance plans excluded any treatments that were not reimbursed under the Saskatchewan Prescription Drug Plan formulary; as such, with these insurance plans, supportive cancer medications (e.g., erythropoiesisstimulating agents and neutropenia treatments) were not reimbursable.

Insurance companies used several strategies to control or limit drug expenditures. Deductibles were in place for 31 (49\%) of the 63 plans and were administered on a perprescription basis (24 plans or $77 \%$ of those with deductibles) or an annual basis (7 plans or 23\%). Per-prescription deductibles ranged from $\$ 0.35$ to $\$ 15.00$ (mean $\$ 9.30,95 \%$ 


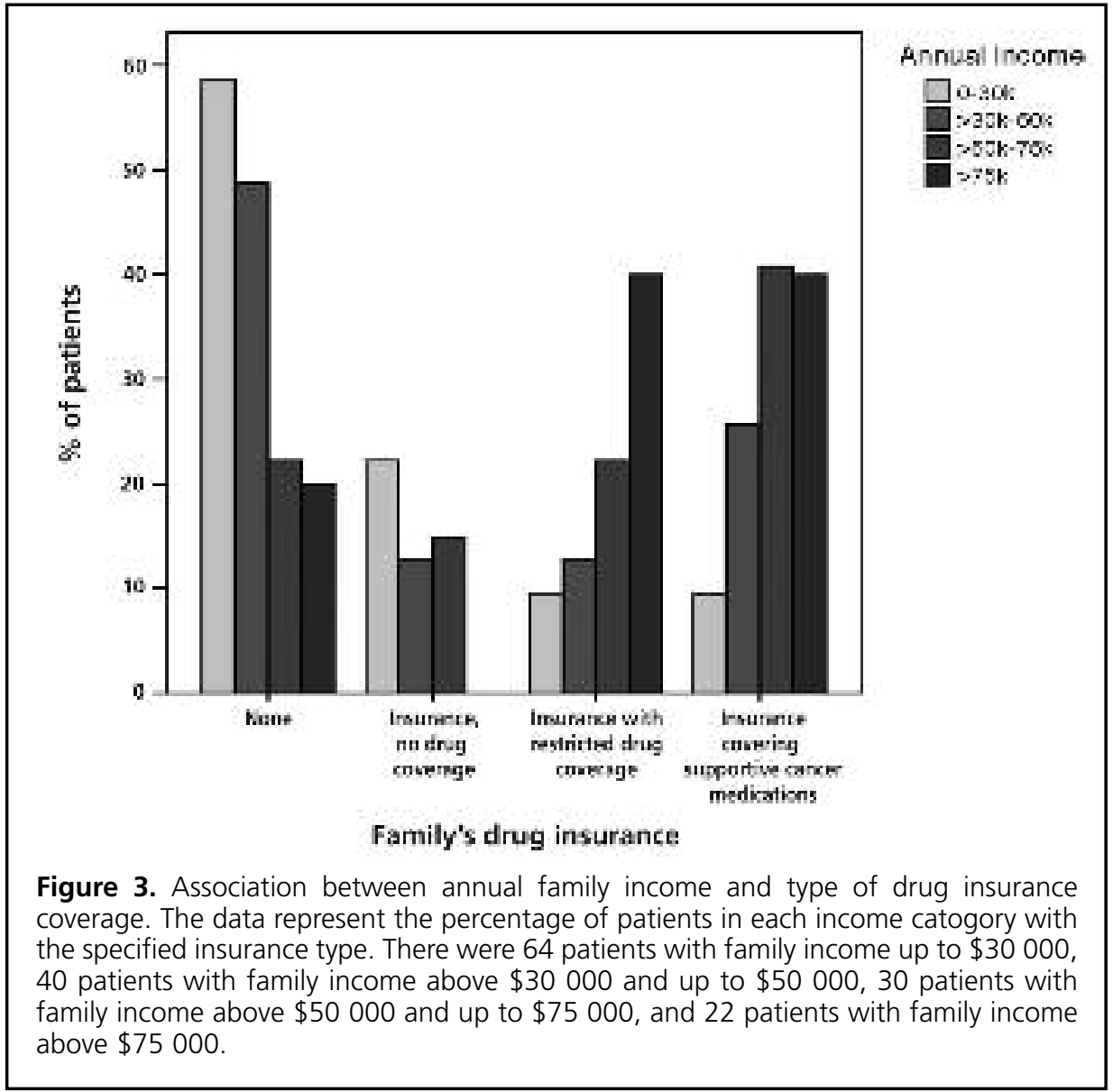

CI $\$ 7.90$ to $\$ 10.70$ ), and annual deductibles ranged from $\$ 15$ to $\$ 400$ per family. Copayments were reported for 28 (44\%) of drug plans. The mean copayment, the portion that patients were required to contribute to the cost of their drugs, was $21.9 \%$ (95\% CI $18.7 \%$ to $25.0 \%$ ). Eleven patients reported that their plans had both a deductible and a copayment. Yearly maximums (range $\$ 750$ to $\$ 1700$ ) were present for 8 (13\%) of the plans, and lifetime maximums (range $\$ 50000 \$ 1$ million) for $3(5 \%)$ of the plans.

\section{Time Required to Assess Patient's Insurance Status}

The mean amount of time ( \pm standard deviation) required to assess whether a patient had access to medical insurance that covered the cost of drugs was $11.0 \pm 9.9 \mathrm{~min}(95 \% \mathrm{CI}$ 9.3-12.6). The mean assessment time for patients with drug insurance was significantly greater than the time for patients with no insurance $(13.3 \pm 10.0$ and $9.2 \pm 9.6 \mathrm{~min}$, respectively; $p=0.02)$. The recorded assessment time included the time required to obtain the patients' written consent to participate in the project and their demographic information.

\section{Associations Between Insurance, Income, and Age}

Patients in the lowest income category (annual income up to $\$ 30000$ ) were the most likely to have no private insurance or insurance with no drug coverage, whereas patients in the highest-income category (annual income above $\$ 75000$ ) were more likely to have insurance that covered medications.

Patients without insurance for medications were older (mean age $61.8 \pm 13.6$ years) than patients with drug coverage (mean age $54.5 \pm 13.2$ years for patients with plans that reimbursed supportive cancer medications and $54.3 \pm 10.3$ years for those with plans not reimbursing supportive cancer medications; $p=0.001$ ). The results of logistic regression showed that age was not a significant predictor of whether a patient would carry private insurance $(p=0.82)$, but income was $(p=0.003)$. Specifically, compared with patients who had an annual income of up to $\$ 50000$, patients with a higher income were at least 5 times more likely to have insurance.

\section{DISCUSSION}

In this survey of patients who presented for chemotherapy at the Saskatoon Cancer Centre, just under one-quarter of 
participants had access to private medical insurance that included reimbursement for supportive cancer care treatments. The likelihood of a patient having private insurance was significantly related to higher income (greater than $\$ 50000$ ), but did not appear to be significantly related to age. The frequency of private insurance in the low-income group was low and may have been due to a high prevalence of unemployment and/or reliance on social assistance in that group; nevertheless, many "low-income" patients did have access to private insurance. This finding demonstrates the importance of distinguishing patients receiving social assistance and those who are unemployed from "low-income" employed patients in future projects to assess private insurance reimbursement for medications.

Although deductibles and other mechanisms to limit costs were common features of the private insurance plans, this study showed that a significant portion of the cost of some supportive cancer medications currently reimbursed by the Saskatchewan Cancer Agency and administered on an outpatient basis ${ }^{5}$ could potentially be transferred to private insurance companies. Access to a multipayer system could allow the Saskatchewan Cancer Agency to reserve public reimbursement for patients who do not have a private drug plan or those whose private drug plan does not cover the cost of specific medications. Most provincial ministries of health offer assistance like this for citizens in need, whereby patients can apply for public reimbursement of their drugs if they have no insurance or if their private insurance does not fully cover the cost of their medications. Under the Trillium Drug Program in Ontario, for example, once the applicable deductible ( $4 \%$ of annual income) is exceeded, the program participant may receive the remaining benefits through the public plan. ${ }^{10}$ This type of coverage is meant to ensure that patients receive the medications that they need; it was not put in place solely to offset public drug costs. Nonetheless, it is a clear example of a mechanism for cost-sharing that already exists.

To the authors' knowledge, there are no other publications reporting on the potential for public payers of health care to share costs with private payers. A report by the Cancer Advocacy Coalition of Canada suggested that an increasing number of new cancer drugs require self-payment or private insurance because of the lack of public funding in some jurisdictions. ${ }^{6}$ A clear pattern exists whereby private reimbursement of cancer drugs is high in the eastern Canadian provinces (where public funding of cancer drugs is relatively low) and relatively low in the western provinces (where coverage of cancer drugs is higher). ${ }^{6}$ One could hypothesize that reimbursement through the private drug plans is maximized in the eastern provinces out of necessity, because there is less public funding; in the West, public funding is more readily available, which results in a diminished need to seek avenues for private coverage even where it probably exists.
An assessment of the feasibility of routinely assessing patients' private insurance coverage and managing the coordination of public versus private drug benefits was beyond the scope of this project. On average, the assessment of patients' access to drug coverage required a minimal amount of time (11 min per patient), and this duration would probably be significantly less in actual practice because the collection of patient demographic information and informed consent would not usually be required. While it appears that a program to assess individual cost-sharing opportunities would be feasible, it remains to be determined whether the required personnel are routinely in place and whether they have dedicated time for this process. It is likely that larger hospitals and cancer centres could find the resources, whereas smaller ones might be limited in their ability to do so. Further study should be conducted to determine whether cost-sharing between cancer agencies and private payers is attainable in actual practice and whether the resources required to administer the program would be completely offset by the provincial payer's drug expenditures that would be spared.

It was also beyond the scope of this project to assess the potential impact on patient outcomes of private insurance copayments, other out-of-pocket expenses for patients, the time that patients had to wait for reimbursement, and the administrative burden of coordinating benefits. It is possible that a systematic shift of costs to private payers could lead to further restrictions within private insurance plans as expenditures increase. Further analysis should be conducted to definitively determine whether the intended benefits of a cost-sharing program could be realized.

As newer, more expensive drugs become available for which government funding is requested, it is becoming increasingly difficult for cancer organizations to obtain adequate funding to provide benefits for the full range of available cancer drugs. ${ }^{6}$ Through routine assessment and follow-up of all patients' access to private insurance (including that of low-income patients), the potential exists to ensure that families who are covered are able to maximize their access to the medications for which they or their employers have already paid fees. Limiting the provision of medications to those who are not insured may offset some costs of medication normally provided by the cancer organization. Cost-sharing with private insurance providers could allow the cancer organizations to reallocate a portion of its budget, thereby freeing up funds for other therapies for the good of all patients. Furthermore, given that some of the private insurance drug plans polled in this survey appeared to follow the provincial formulary, there is even greater probability of private insurance covering more drugs if those drugs were to be formally listed by the Saskatchewan Prescription Drug Plan. 
By optimally utilizing the available multipayer environment (public and private) and ensuring that the Saskatchewan Cancer Agency would be the payer of last resort, there may be greater opportunity for patients to receive outpatient cancer and supportive care therapies developed in the future. However, further study is required to determine whether a cost-sharing program would be cost-effective and in the best interest of patients.

\section{References}

1. Canada Health Act: overview. Ottawa (ON): Health Canada; 2004 Oct 1 [cited 2009 May 7]. Available from: http://www.hc-sc.gc.ca/ hcs-sss/medi-assur/cha-lcs/overview-apercu-eng.php

2. Drug expenditure in Canada 1985 to 2006. Ottawa (ON): Canadian Institute for Health Information; 2007 [cited 2008 Mar 21]. Available from: http://secure.cihi.ca/cihiweb/products/Drug_Expenditure_in_ Canada_2007_e.pdf

3. Anis AH, Guh D, Wang Xh. A dog's breakfast: prescription drug coverage varies widely across Canada. Med Care 2001;39(4):315-326.

4. MacDonald K, Potvin K. Interprovincial variation in access to publicly funded pharmaceuticals: a review based on the WHO Anatomical Therapeutic Chemical classification system. Can Pharm J 2004;137(7):29-24.

5. Reimbursement/coverage information for medications used in cancer treatment. In: Drug coverage.ca: a guide to reimbursement. Plasmid Biocommunications Inc.; 2004-2007 [cited 2008 Mar 21]. Available from: http://www.drugcoverage.ca/p_cancercover_table.asp?language =1

6. Khoo K, Colucci R, Hryniuk W, Ragaz J, Sehdev S, Savage C. Cancer drug access: part three. The new wave of cancer drugs. In: Report card on cancer in Canada, 2007. Toronto (ON): Cancer Advocacy Coalition of Canada; 2007 [cited 2008 Apr 14]. p 40-52. Available from: http://www.canceradvocacy.ca/reportcard/2007/ Cancer\%20Drug\%20Access,\%20Part\%20Three.pdf

7. Sheehy O, LeLorier J, Rinfret S. Restrictive access to clopidogrel and mortality following coronary stent implantation. CMAJ 2008;178(4): 413-420.

8. Dorais M, LeLorier J. Impact of the socioeconomic status on the probability of receiving formulary restricted thiazolidinediones (TZDs). Can J Clin Pharmacol 2008;15(1):e15-e21.

9. 2005 Saskatchewan Cancer Agency annual report. Saskatoon (SK): Saskatchewan Cancer Agency; 2005 [cited 2008 Jul 11]. Available from: http://www.scf.sk.ca/AnnualReport/Saskatchewan\%20Cancer\% 20Agency\%202004-05\%20Annual\%20Report.pdf
10. A guide to understanding the Trillium Drug Program. Toronto (ON): Ontario Ministry of Health and Long-Term Care; 2007 [cited 2008 Jul 8]. Available from: http://www.forms.ssb.gov.on.ca/ $\mathrm{mbs} / \mathrm{s} \mathrm{s}$ b/form s/s sbforms.nsf/Attach Docs Publish/ 014-S46850E-87 15/\$File/trillium_bookE_.pdf

Lindy Forte, MSc, is a Reimbursement Consultant for VALORE Consulting, Toronto, Ontario.

Colleen Olson, BSc(Pharm), is a Senior Pharmacist with the Saskatoon Cancer Centre, Saskatoon, Saskatchewan.

Carolyn Atchison, MSc, is Senior Manager, International Health Economics and Reimbursement, Amgen (Europe) $\mathrm{GmbH}$, Zug, Switzerland.

Kathy Gesy, BSP, MSc(Pharm), is Provincial Leader, Oncology Pharmacy Services, Saskatchewan Cancer Agency, Saskatoon, Saskatchewan.

\section{Address correspondence to:}

Kathy Gesy

Oncology Pharmacy Services

Saskatchewan Cancer Agency

248-111 Research Drive

Saskatoon SK

S7N 3R2

e-mail: kathy.gesy@saskcancer.ca

\section{Acknowledgements}

We thank University of Saskatoon pharmacy students Ashleigh Krislock, Kristen Briggs, and Erin Karakochuk for conducting all of the patient interviews and for following up with the insurance companies; Laurel Duquette of the Department of Statistics at the University of Toronto for conducting all of the statistical analyses; and the patients who participated in this project. The results from this project may contribute to influencing change that could help the Saskatchewan Cancer Agency and its patients.

Amgen Canada Inc provided funding and administrative support for the study. 